\title{
DEGRADAÇÃO DE ESPÉCIES NITROAROMÁTICAS E REMEDIAÇÃO DE EFLUENTES DA INDÚSTRIA DE EXPLOSIVOS, UTILIZANDO-SE PROCESSOS REDUTIVOS-OXIDATIVOS FUNDAMENTADOS NO USO DE FERRO METÁLICO
}

\author{
Luiz Fernando Rocha Cavalotti e Patricio Peralta-Zamora* \\ Departamento de Química, Universidade Federal do Paraná, CP 19081, 81531-990 Curitiba - PR, Brasil \\ Marcio Barreto Rodrigues \\ Universidade Tecnológica Federal do Paraná, CP 116, 85503-390 Pato Branco - PR, Brasil \\ Teresa Cristina Brazil de Paiva \\ Escola de Engenharia de Lorena, Universidade de São Paulo, CP 116, 12602-810 Lorena -SP, Brasil
}

Recebido em 30/7/08; aceito em 27/1/09; publicado na web em 3/7/09

\begin{abstract}
DEGRADATION OF NITROAROMATIC COMPOUNDS AND REMEDIATION OF RESIDUES FROM THE EXPLOSIVE PRODUCTION BY REDUCTIVE-OXIDATIVE PROCESSES BASED ON ZERO-VALENT IRON. In this work the potentiality of reductive-oxidative processes based on zero-valent iron was studied aiming the degradation of nitroaromatic compounds and the remediation of residues from the explosive industry. The reductive process was applied as a continuous treatment system, using steel-wool as zero-valent iron source. The process permitted an almost total degradation of nitrobenzene, nitrophenol, nitrotoluene, dinitrotoluene and trinitrotoluene, probably with generation of the respective amine-derivative. The yellow-water residue, containing soluble trinitrotoluene, was notably modified by the reductive process, a fact that permitted a substantial enhancement of its biodegradability. Furthermore, the subsequent photo-Fenton process allowed TOC removal of about $80 \%$.
\end{abstract}

Keywords: zero-valent iron; photo-Fenton; nitroaromatics.

\section{INTRODUÇÃO}

Em função da sua versatilidade, ${ }^{1}$ compostos nitroaromáticos são maciçamente utilizados em diversos segmentos industriais, incluindo a produção de tintas, plásticos, produtos farmacêuticos e de uso veterinário, alimentos e explosivos. ${ }^{2,3}$ Dentro desta última categoria destacam-se os compostos aromáticos polinitrados, ${ }^{4-7}$ largamente utilizados na produção de munição e outros equipamentos militares. ${ }^{8}$

Com uma produção mundial estimada em 108 toneladas/ano, compostos nitroaromáticos aparecem como importantes agentes de contaminação ambiental, destacando-se pela sua elevada resistência à degradação microbiana e pelos efeitos deletérios provocados nos sistemas ecológicos contaminados. ${ }^{9-13}$ Em geral, admite-se que espécies nitroaromáticas sejam responsáveis por efeitos crônicos de relevância, como carcinogênese e mutagenicidade.

De maneira geral, a toxicidade e persistência destas espécies aumenta com o aumento do número de substituintes nitro. ${ }^{14}$ Desta forma, espécies polinitradas caracterizam-se por elevada toxicidade e extrema resistência frente aos processos convencionais de degradação. ${ }^{15}$

No Brasil, a produção de explosivos nitroaromáticos concentra-se nos estados de São Paulo, Paraná e Minas Gerais. ${ }^{8}$ O 2,4,6-trinitrotolueno (TNT) é produzido por nitração sequencial do tolueno, reação realizada em três estágios e na presença de ácido nítrico e sulfúrico. A formação do composto trinitrado ocorre somente no terceiro estágio, juntamente com diversas impurezas, as quais são retiradas do produto por sucessivas lavagens com água. Na primeira lavagem obtém-se um resíduo denominado água amarela (AA), constituído de diversos produtos de oxidação (ex., nitrofenóis, ácido trinitrobenzóico e tetranitrometano) e TNT simétrico dissolvido. Na segunda lavagem, realizada com sulfito de sódio, origina-se a água vermelha (AV), contendo diversas formas assimétricas do TNT. ${ }^{15}$

\footnotetext{
*e-mail: zamora@quimica.ufpr.br
}

O tratamento de resíduos contendo espécies químicas desta natureza é bastante dificultado pelo seu marcado caráter tóxico. ${ }^{16,17}$ Adicionalmente, o caráter elétron-deficiente destas espécies dificulta a degradação oxidativa, ${ }^{18}$ fato que, em princípio, torna a via redutiva mais interessante. Em geral, admite-se que processos redutivos mediados por ferro metálico possam facilitar o tratamento convencional de compostos nitrados, em razão da formação de aminas de maior biodegradabilidade (Equação 1). ${ }^{19}$

$\mathrm{ArNO}_{2}+3 \mathrm{Fe}^{0}+\mathrm{H}^{+} \rightarrow \mathrm{ArNH}_{2}+3 \mathrm{Fe}^{2+}+2 \mathrm{H}_{2} \mathrm{O}$

Adicionalmente, a formação de íon ferroso viabiliza a posterior aplicação de processos Fenton, o que pode complementar a degradação dos substratos, por vias oxidativas. A conveniência de processos redutivos-oxidativos aplicados em sequência foi demonstrada por Seok-Young e colaboradores, ${ }^{20}$ estudando a degradação de TNT. Em geral, a redução preliminar favorece a degradação oxidativa subsequente, estendendo-se a mineralização de 20 a $60 \%$. Efeitos similares foram observados por Raja e colaboradores, ${ }^{21}$ estudando a degradação de compostos organoclorados. Nestas condições, o processo redutivo preliminar permitiu praticamente duplicar a mineralização de 4-clorofenol, quando da aplicação de um processo foto-Fenton posterior.

Um esquema que representa as possíveis vias reacionais em um sistema redutivo-oxidativo fundamentado no uso de ferro metálico é apresentado na Figura 1. Neste sistema, reações de redução são viabilizadas pelos elétrons liberados na oxidação do ferro a íon ferroso, pela oxidação do íon ferroso a férrico e pela corrosão mediada pela água, com concomitante produção de hidrogênio. ${ }^{22}$ Subsequentemente, substratos reduzidos poderão ser oxidados por processos Fenton (Equação 2), foto-Fenton (Equação 3) e tipo-Fenton (Equações 4 e 5), mediados por íon ferroso, íon férrico e óxidos férricos que tendem a passivar a superfície do ferro metálico. 


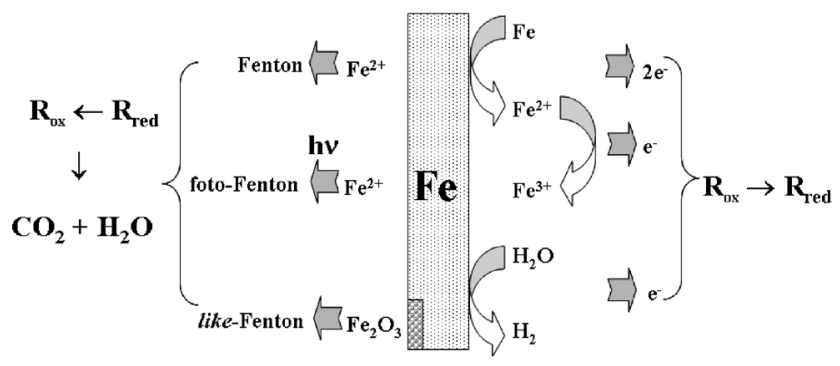

Figura 1. Representação esquemática das vias reacionais (redutivas e oxidativas) viabilizadas pelo uso de ferro metálico

(Fenton): $\mathrm{Fe}^{2+}+\mathrm{H}_{2} \mathrm{O}_{2} \rightarrow \mathrm{Fe}^{3+}+\mathrm{HO}^{-}+\mathrm{HO}^{*}$

(Foto-Fenton): $\mathrm{Fe}^{3+}+\mathrm{H}_{2} \mathrm{O}+\mathrm{hv} \rightarrow \mathrm{Fe}^{2+}+\mathrm{H}^{+}+\mathrm{HO}^{*}$

(Tipo-Fenton): $\mathrm{X}-\mathrm{Fe}^{3+}+\mathrm{H}_{2} \mathrm{O}_{2} \rightarrow \mathrm{X}-\mathrm{Fe}^{2+}+\mathrm{HO}_{2} \cdot+\mathrm{H}^{+}$

$\mathrm{X}-\mathrm{Fe}^{2+}+\mathrm{H}_{2} \mathrm{O}_{2} \rightarrow \mathrm{X}-\mathrm{Fe}^{3+}+\mathrm{OH}^{-}+\mathrm{HO}^{\bullet}$

Neste trabalho, a potencialidade do processo redutivo fundamentado no uso de ferro metálico foi avaliada em relação à degradação de compostos nitroaromáticos e à remediação de resíduos líquidos oriundos do processo de fabricação de TNT (água amarela). A eficiência de processos foto-Fenton subsequentes também foi avaliada, objetivando-se a completa remediação dos resíduos em questão.

\section{PARTE EXPERIMENTAL}

\section{Reagentes}

Nitrobenzeno, nitrofenol, nitrotolueno, dinitrotolueno e trinitrotolueno foram de grau de pureza P.A., sendo utilizados em solução aquosa de concentração $6,52 \times 10^{-4} \mathrm{~mol} \mathrm{~L}^{-1}$.

Como fonte de ferro metálico foram utilizados ferro em pó (Vetec, 99\%, 195 mesh) e fibras de aço-carbono, comercialmente distribuídas como lã de aço. Objetivando-se retirar óxidos que depositam na sua superfície, as fibras foram previamente lavadas com solução aquosa de $\mathrm{HCl}$ ou $\mathrm{H}_{2} \mathrm{SO}_{4}(10 \%$ v/v).

Peróxido de hidrogênio (Peróxidos do Brasil, 30\% m/m) foi utilizado como recebido, sendo conservado sob refrigeração. A sua concentração foi verificada periodicamente por titulação permanganométrica.

Outros reagentes (ácidos, bases e sais) foram de grau analítico P.A.

O efluente em estudo (água amarela) foi cedido pela IMBEL (Indústria de Material Bélico do Brasil), apresentando pH de 1,2 e DQO de $18.876 \mathrm{mg} \mathrm{O} \mathrm{L}^{-1}$.

\section{Procedimento experimental}

A primeira etapa do trabalho, desenvolvida para verificar o efeito da massa e da natureza do ferro metálico, foi conduzida no modo batelada com agitação orbital, utilizando-se nitrobenzeno como substrato padrão. Neste estudo, amostras de $100 \mathrm{~mL}$ foram adicionadas de quantidades diversas de ferro metálico em pó e lã de aço comercial, e agitadas à velocidade de $150 \mathrm{rpm}$.

Na segunda etapa do trabalho, desenvolvida para avaliar a degradação das espécies nitroaromáticas e a remediação dos resíduos em estudo, o processo redutivo foi aplicado no modo contínuo, utilizando-se a aparelhagem esquematizada na Figura 1S (Material Suplementar). O sistema foi constituído de uma coluna de vidro de 28 $\mathrm{cm}$ de comprimento, $2 \mathrm{~cm}$ de diâmetro interno e $100 \mathrm{~mL}$ de volume útil, recheada com $14 \mathrm{~g}$ de lã de aço. A amostra foi inserida na coluna com auxílio de uma bomba peristáltica, com vazão de $15 \mathrm{~mL} \mathrm{~min}{ }^{-1}$.

$\mathrm{O}$ processo de degradação oxidativa subsequente (foto-Fenton) foi conduzido em um reator fotoquímico de bancada, equipado com refrigeração a água e sistema de agitação magnética. A radiação foi proporcionada por uma lâmpada a vapor de mercúrio de $125 \mathrm{~W}$, inserida na solução com ajuda de um bulbo de vidro Pyrex (radiação UV-A). Após passar pelo processo redutivo, as amostras foram caracterizadas em relação ao teor de ferro solúvel, acidificadas até $\mathrm{pH} 3$, adicionadas de peróxido de hidrogênio $\left(200 \mathrm{mg} \mathrm{L}^{-1}\right)$ e submetidas à irradiação.

Em todos os casos, alíquotas foram coletadas em intervalos regulares, filtradas em membrana de acetato de celulose (Milipore, $0,45 \mu \mathrm{m})$ e submetidas a controle analítico.

\section{Controle analítico}

A degradação dos substratos nitroaromáticos foi avaliada por cromatografia líquida de alta eficiência, utilizando cromatógrafo Varian Pró-Star, equipado com coluna Microsorb-MV 100-5 C18 (250 x 4,6 mm) e detector UV-Vis (225 nm). Como fase móvel foi utilizada mistura metanol/água (50:50), acidificada com $1 \mathrm{~mL}$ de $\mathrm{H}_{3} \mathrm{PO}_{4}$. Monitoramentos foram também realizados por espectroscopia eletrônica, utilizando-se espectrofotômetro HP 8452-A Diode Array e cubetas de quartzo de $1 \mathrm{~cm}$ de caminho óptico.

Determinações de $\mathrm{Fe}^{2+}$ e $\mathrm{Fe}^{3+}$ foram realizadas espectrofotometricamente, utilizando-se metodologia fundamentada na complexação de $\mathrm{Fe}^{2+}$ com 1,10-fenantrolina. ${ }^{23}$

Determinações de carbono orgânico total foram realizadas em um analisador de carbono orgânico total Shimadzu TOC-VCPH, fundamentado em oxidação catalítica a elevadas temperaturas e determinação de $\mathrm{CO}_{2}$ por espectroscopia no infravermelho.

A toxicidade dos resíduos foi avaliada através de bioensaio, envolvendo Artemia salina sp. O teste foi aplicado de acordo com metodologia regulamentada pelo CONTEC 2588 (1996). ${ }^{24,25}$

Para avaliar a biodegradabilidade dos resíduos em estudo foi utilizado o teste de biodegradabilidade inerente (Zahn-Wellens), aplicado de acordo com procedimento recomendado na literatura. ${ }^{26}$ Neste procedimento, a substância em avaliação é colocada em contato com uma elevada quantidade de Iodo não aclimatado (concentração bacteriana de $1 \mathrm{~g} \mathrm{~L}^{-1}$ ), na presença de nutrientes minerais e aeração constante. A evolução da carga orgânica solúvel (demanda química de oxigênio) é avaliada durante 28 dias, em intervalos regulares.

\section{RESULTADOS E DISCUSSÃO}

\section{Degradação de nitrobenzeno em batelada}

Nos últimos anos, a eficiência da degradação redutiva de substratos de relevância ambiental tem sido bastante documentada, principalmente utilizando-se ferro metálico em pó. Uma vez que o presente projeto objetiva avaliar a potencialidade do sistema em relação à remediação de resíduos industriais contendo espécies nitroaromáticas, tornou-se interessante, em primeiro lugar, avaliar a eficiência de diferentes fontes de ferro, na procura de insumos que pudessem baratear o processo e facilitar a elaboração de um sistema de tratamento contínuo.

Assim, um estudo comparativo foi realizado, avaliando-se a eficiência de degradação de ferro em pó e lã de aço comercial, frente a soluções aquosas de nitrobenzeno, utilizadas como substrato padrão. O estudo foi realizado por meio de um sistema de planejamento fatorial de experimentos, o que permitiu avaliar em paralelo o efeito da massa de agente redutor. Os resultados, expressos como remoção de nitrobenzeno em 30 min de reação, foram avaliados por cromatografia líquida, sendo apresentados na Figura 2. 


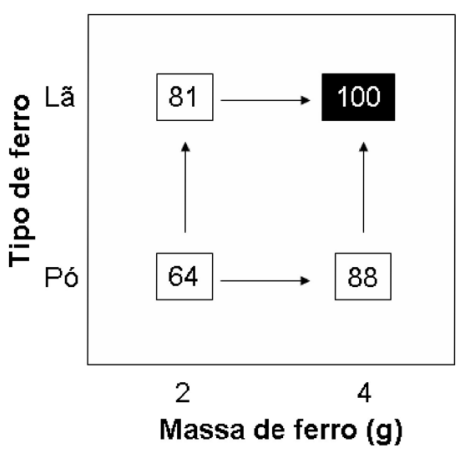

Efeito da massa: $(-64+88-81+100) / 2=+22 \pm 3$

Efeito do tipo de ferro: $(-64+81-88+100) / 2=+14 \pm 3$ Efeito massa $x$ tipo: $(+64-88-81+100) / 2=-2,5 \pm 3$

Figura 2. Representação geométrica do planejamento fatorial $\left(2^{2}\right)$ utilizado para avaliar o efeito do tipo e da massa de ferro metálico na degradação redutiva de nitrobenzeno (Sistema: batelada, Agitação: orbital, $p H$ : 5,0, Tempo de reação: 30 min, Monitoramento: cromatografia líquida)

Estes resultados, apresentados na forma de uma representação geométrica, e os efeitos apresentados na sequência indicam que a evolução de ambos parâmetros do nível inferior para o superior implica em efeitos positivos, relacionados com uma maior capacidade de degradação. Isto é, quando o ferro em pó é substituído por lã de aço, a degradação de nitrobenzeno aumenta, em média, 14 pontos percentuais. O efeito da massa é ainda maior, provocando aumentos de 22 pontos percentuais.

O efeito positivo do aumento da massa era esperado, principalmente em razão da maior disponibilidade de sítios reativos. Diferentemente, o melhor desempenho da lã de aço representou uma surpresa, sobretudo se considerarmos a inexistência de propostas de tratamento redutivo recorrendo-se a este tipo de material. Possivelmente, a menor eficiência do sistema fundamentado no uso de ferro em pó esteja relacionada com a sua precoce passivação, em razão da sua elevada área superficial. Em geral, a formação de óxidos passivantes na superfície do redutor representa um dos maiores problemas neste tipo de processos.

É importante salientar que os processos foram aplicados em pH 5, seguindo as recomendações que surgiram em estudos anteriores. A este respeito, Souza e Peralta- Zamora ${ }^{27}$ comentam que, embora a eficiência de degradação seja maior em valores de $\mathrm{pH}$ mais baixos, a consequente geração de quantidades exageradas de ferro solúvel (entre 100 e $500 \mathrm{mg} \mathrm{L}^{-1}$ ) obriga à disponibilização de processos subsequentes para a remoção do excesso de ferro. Em pH 5 a eficiência de degradação é levemente sacrificada, mas a concentração de ferro solúvel é mantida em valores compatíveis com o descarte.

O monitoramento espectroscópico do processo redutivo evidencia uma significativa redução da larga banda que caracteriza nitrobenzeno (centrada em $275 \mathrm{~nm}$ ), assim como o surgimento de duas bandas centradas em 229 e 280 nm (Figura 3), compatíveis com a presença de anilina. ${ }^{25}$ Por sua vez, os estudos realizados para avaliar a toxicidade indicaram inocuidade do produto de partida ( $100 \%$ de sobrevivência em 24 e 48 h de exposição), assim como forte efeito tóxico dos produtos de degradação redutiva (75\% de mortalidade para 24 h e $100 \%$ em 48 de exposição). Finalmente, o monitoramento cromatográfico atestou a completa degradação de nitrobenzeno e confirmou a presença de anilina, como principal produto de degradação. Trata-se de um resultado que explica a evolução dos espectros eletrônicos e a toxicidade aguda observada.

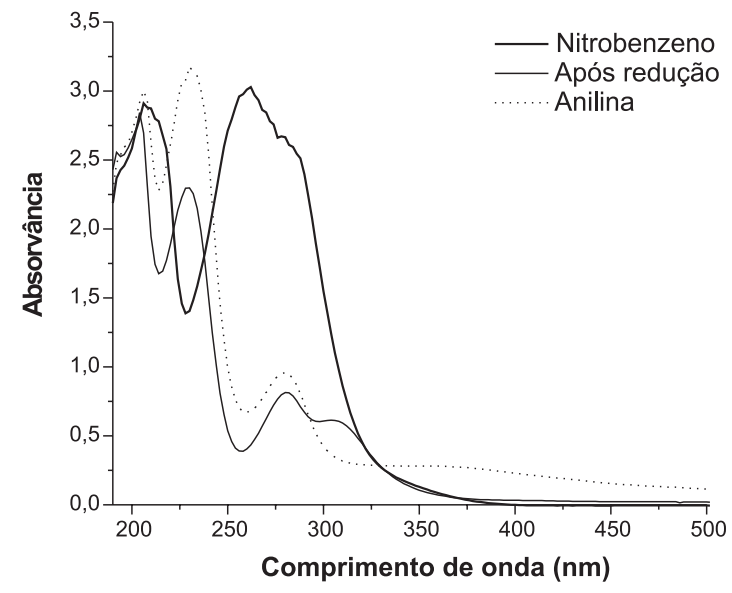

Figura 3. Variação espectral do nitrobenzeno durante degradação redutiva (Sistema: batelada, Agitação: orbital, pH: 5,0, Tempo de reação: $30 \mathrm{~min}$, Monitoramento: espectroscopia eletrônica)

É importante salientar neste momento, que os processos redutivos não induzem à mineralização dos substratos, mas apenas a sua modificação. Embora esta modificação possa favorecer sua biodegradabilidade, o acompanhamento da toxicidade torna-se importante, principalmente em razão da possibilidade de se formarem produtos de maior toxicidade. Deste ponto de vista, a aplicação de processos oxidativos sequenciais aparece como uma necessidade, de maneira a garantir a completa remediação dos resíduos em questão.

\section{Degradação de nitroaromáticos em coluna}

Em função dos resultados preliminares, processos redutivos no modo contínuo foram aplicados na presença de lã de aço. Trabalhando-se com uma vazão de aproximadamente $15 \mathrm{~mL} \mathrm{~min}^{-1}$, cada um dos substratos foi submetido a um tempo de retenção de aproximadamente $5 \mathrm{~min}$, observando-se os resultados de degradação apresentados na Figura 4. De maneira geral, a análise cromatográfica demonstra a degradação praticamente completa de todos os substratos em estudo, em todos os tempos monitorados, assim como o surgimento de produtos de degradação que apresentam sinais de grande intensidade. Embora a identificação não tenha sido realizada, é possível assumir a geração de derivados aminados, como anilina, ${ }^{25}$ aminofenol, ${ }^{26}$ aminotolueno, ${ }^{27}$ aminonitrotolueno ${ }^{10}$ e aminodinitrotolueno, ${ }^{28}$ na degradação de nitrobenzeno, nitrofenol, nitrotolueno, dinitro e trinitrotolueno, respectivamente.

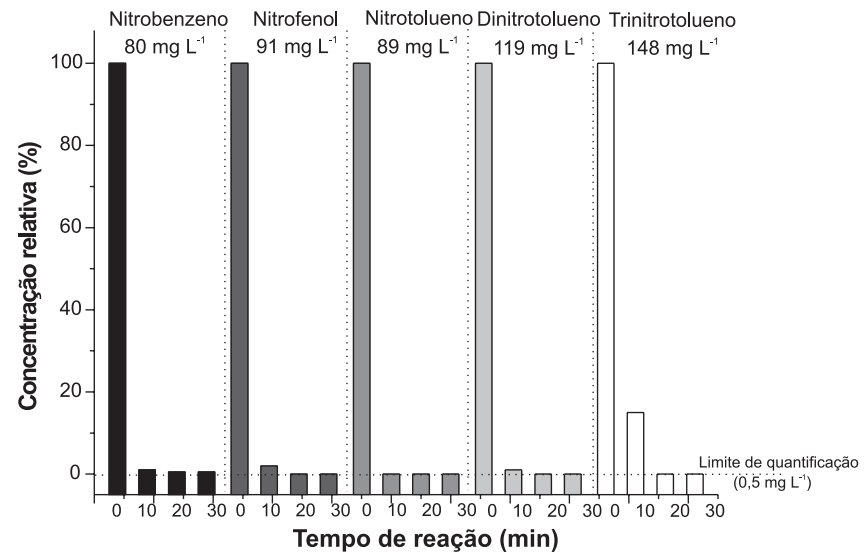

Figura 4. Diminuição da concentração de nitroaromáticos durante degradação redutiva (Sistema: contínuo, Vazão: $15 \mathrm{~mL} \mathrm{~min}^{-1}$, pH: 5,0, Monitoramento: cromatografia líquida) 
Embora a natureza aminada dos produtos de reação seja admitida universalmente, antecedentes da literatura indicam que as vias reacionais podem ser influenciadas pelo tipo de ferro metálico utilizado. Jafarpour e colaboradores, ${ }^{29}$ por exemplo, identificaram o 4-amino2-nitrotolueno como principal produto da degradação redutiva de 2,4-dinitrotolueno, utilizando ferro de alta pureza. Por sua vez, o uso de ferro fundido levou à geração de 2-amino-4-nitrotolueno.

No decorrer deste estudo ficou evidente a perda de eficiência do sistema com o passar do tempo, provavelmente em função da passivação provocada pela formação de óxidos na superfície do ferro ${ }^{30} \mathrm{ou}$ pela adsorção de substratos e/ou de produtos de reação. Em função deste fato, recomenda-se a inserção de ciclos periódicos de lavagem, utilizando-se soluções diluídas de $\mathrm{HCl}^{31}$

O monitoramente de formas solúveis de ferro (II e III) indicou concentrações entre 30 e $80 \mathrm{mg} \mathrm{L}^{-1}$, o que corresponde a valores que extrapolam a quantidade máxima permitida por lei para o descarte de resíduos $\left(15 \mathrm{mg} \mathrm{L}^{-1}\right) .{ }^{32}$ Para contornar este problema, duas alternativas podem ser utilizadas: a redução do tempo de permanência da amostra no interior da coluna reativa ou a eliminação do ferro excedente por precipitação.

Em todos os casos, a redução do teor de carbono orgânico dissolvido propiciada pelo processo redutivo foi pouco significativa, o que, mais uma vez, indica a necessidade de procedimentos complementares que permitam a mineralização.

Aproveitando-se a geração de elevadas concentrações de íon ferroso, processos oxidativos do tipo foto-Fenton foram aplicados na sequência, utilizando-se radiação UV-A e peróxido de hidrogênio em concentração de $200 \mathrm{mg} \mathrm{L}^{-1}$. Neste estudo foi avaliada a degradação de apenas dois substratos: nitrobenzeno, considerado padrão, e trinitrotolueno, espécie majoritariamente presente nos resíduos industriais em questão. Os resultados, apresentados na forma de uma sequência de espectros eletrônicos (Figura 5), confirmam a significativa modificação química das moléculas em estudo, quando submetidas ao processo redutivo. Contudo, o forte sinal remanescente confirma a incapacidade de mineralização do sistema redutivo, o que implica na formação de produtos que mantêm o seu caráter aromático. Por sua vez, o tratamento oxidativo permite a degradação praticamente completa das espécies aromáticas, o que se manifesta como remoção dos sinais espectrais registrados entre 200 e $300 \mathrm{~nm}$. O sinal residual observado na região ultravioleta (centrado em $200 \mathrm{~nm}$ ) pode ser devido à presença de espécies de baixo peso molecular, tipicamente ácidos orgânicos, ${ }^{33}$ ou de formas solúveis de ferro, que também absorvem nesta região espectral.

Apesar da drástica redução das bandas de absorção, o processo oxidativo não foi eficiente em reduzir a concentração de carbono orgânico total. Reduções máximas de cerca de 70 e $50 \%$ foram observadas, nos estudos de degradação de nitrobenzeno e trinitrotolueno, respectivamente.

Estudos adicionais para avaliar a toxicidade aguda foram realizados, utilizando-se A. salina como organismos teste em 24 e $48 \mathrm{~h}$ de exposição. Os resultados confirmam a baixa toxicidade do nitrobenzeno (100\% de sobrevivência), a maior toxicidade dos produtos de redução, majoritariamente nitrosobenzeno, hidroxiaminobenzeno e anilina, ${ }^{19}(75 \%$ de mortalidade para $24 \mathrm{~h}$ e $100 \%$ em $48 \mathrm{~h}$ de exposição) e a eliminação da toxicidade pelo processo combinado (100\% de sobrevivência). Esta última característica atesta a degradação das estruturas aromáticas e garante a inocuidade dos produtos de degradação. Características diferentes foram observadas na degradação de trinitrotolueno. Em primeiro lugar, o substrato mostra-se tóxico, provocando a morte de todos os organismos teste nos tempos monitorados. O processo redutivo levou à geração de produtos de menor toxicidade ( $80 \%$ de sobrevivência em 24 h e $70 \%$ em 48 h de exposição), enquanto que o processo integrado permitiu a completa inocuidade do resíduo tratado (100\% de sobrevivência).
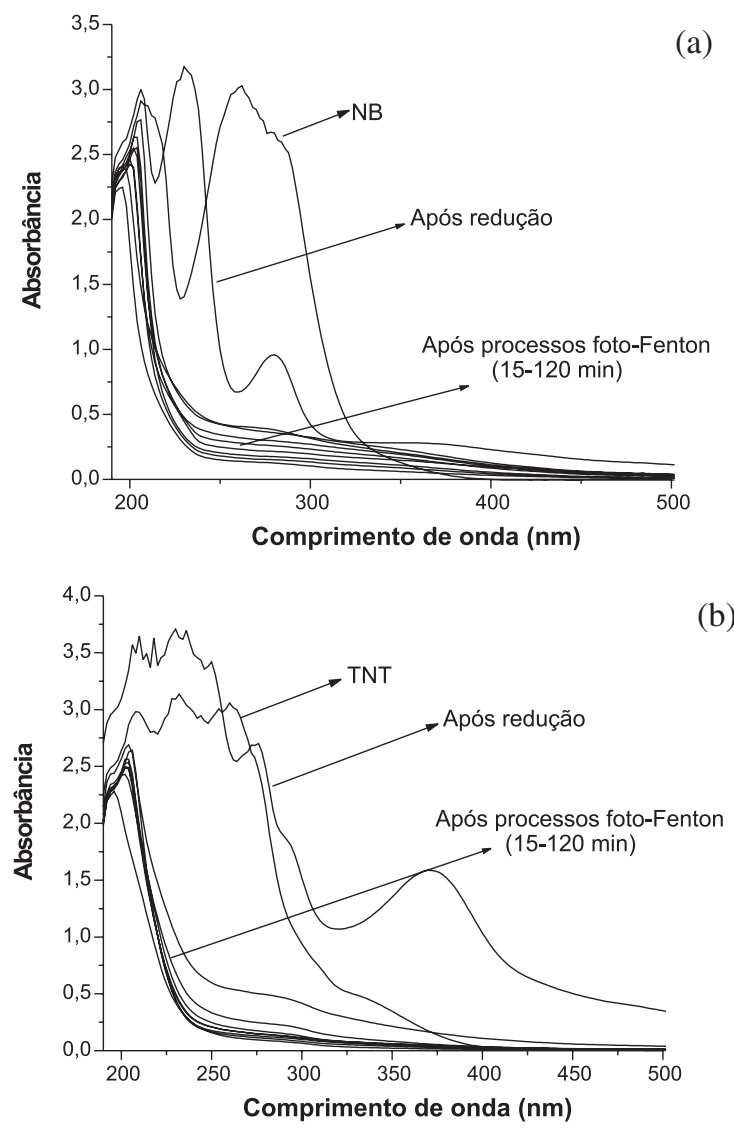

Figura 5. Variação espectral de nitrobenzeno (A) e trinitrotolueno (B) durante degradação redutiva (Sistema: contínuo, Vazão: $15 \mathrm{~mL} \mathrm{~min}^{-1}$, pH: 5,0, Monitoramento: espectroscopia eletrônica)

\section{Remediação do efluente água amarela da indústria de explosivos}

O efluente em estudo (água amarela) apresentou elevada carga

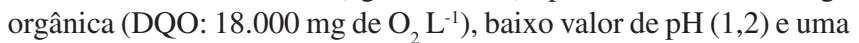
concentração de TNT solúvel de $7,81 \times 10^{-4} \mathrm{~mol} \mathrm{~L}^{-1}$.

Os resultados obtidos na avaliação da biodegradabilidade inerente (método de Zahn-Wellens) são apresentados na Figura 6. Estes resultados demonstram a viabilidade da semente de lodo ativado utilizada no estudo, o que se manifesta como eficiente degradação do etileno glicol, utilizado como substrato de controle. Adicionalmente, o estudo confirma a baixa biodegradabilidade do resíduo em estudo, o que implica uma redução praticamente nula do teor de DQO durante os 28 dias do ensaio. Na avaliação do resíduo submetido ao processo redutivo foi possível observar uma rápida remoção de DQO nos primeiros 6 dias do ensaio, alcançando-se valores da ordem de $50 \%$. Adicionalmente, resíduos de TNT solúvel não foram detectados no resíduo submetido ao tratamento redutivo. Este comportamento atesta a degradação redutiva dos substratos contidos no efluente, com formação de espécies de maior biodegradabilidade, que podem ser convenientemente tratadas pelos sistemas biológicos convencionais usualmente disponíveis no meio industrial.

Como esperado, o processo redutivo não contribuiu com a remoção da DQO. Diferentemente, o processo foto-Fenton aplicado na sequência permitiu a remoção de aproximadamente $50 \%$ da carga orgânica inicial, em tratamentos de $60 \mathrm{~min}$. Neste processo, o consumo de peróxido de hidrogênio ocorre rapidamente, o que diminui a eficiência do processo com o passar do tempo. Desta forma, maiores taxas de degradação podem ser obtidas com a adição contínua deste 
agente. Em geral, duas adições de peróxido (tempo zero e $60 \mathrm{~min}$ ) viabilizam a remoção de aproximadamente $80 \%$ da carga orgânica, em tempos de reação de 120 min.

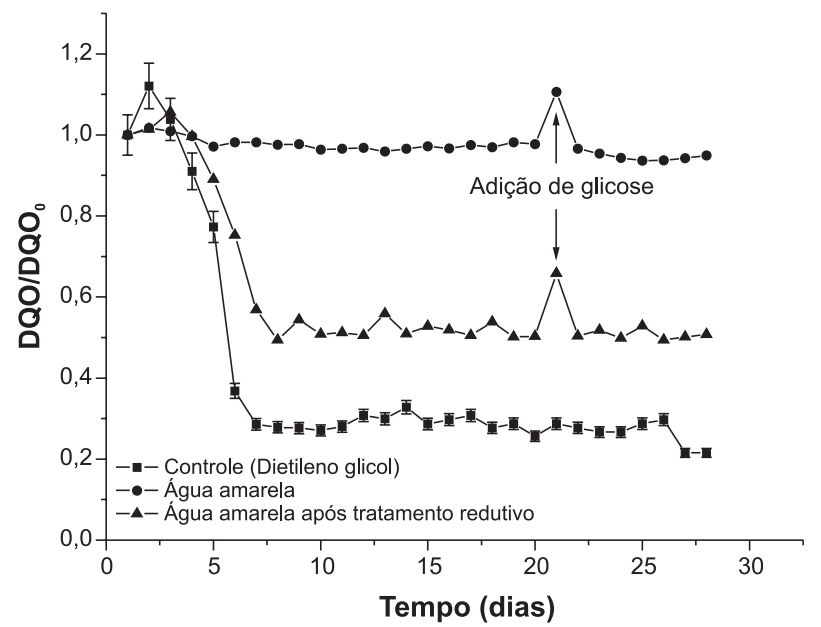

Figura 6. Variação da demanda química de oxigênio em função do tempo, durante a avaliação da biodegradabilidade inerente (método de Zahn-Wellens) de amostras de água amarela bruta e tratada redutivamente

Nos primeiros 30 min do processo oxidativo foi observado um máximo de concentração de formas fenólicas, as quais foram completamente removidas em maiores tempos de reação (90 min). Trata-se de uma observação que atesta um mecanismo de degradação mediado pela hidroxilação do anel benzênico, seguida, de acordo com antecedentes da literatura,${ }^{34} \mathrm{de}$ abertura do anel e formação de ácidos carboxílicos.

\section{CONCLUSÕES}

Os resultados apresentados confirmam uma elevada capacidade dos processos redutivos fundamentados no uso de ferro metálico, em relação à degradação de espécies nitroaromáticas. Dentro deste contexto, o uso de lã de aço apresenta-se especialmente conveniente, não apenas em função do baixo custo, mas principalmente em razão de viabilizar a aplicação de processos contínuos. Nestas condições, todos os substratos em estudo foram eficientemente degradados, provavelmente com formação dos respectivos derivados aminados.

A degradação redutiva de resíduos da produção de explosivos (água amarela) permite importantes aumentos de biodegradabilidade, o que favorece a aplicação de processos biológicos subsequentes. A remoção de matéria orgânica, entretanto, requer processos oxidativos complementares (reação de Fenton), favorecidos pela geração preliminar de espécies ferrosas. Processos foto-Fenton viabilizam a remoção de grande parte da matéria orgânica $(>80 \%)$, principalmente quando se adotam sistemas de múltiplas adições de peróxido de hidrogênio.

\section{MATERIAL SUPLEMENTAR}

Na Figura 1S apresenta-se uma representação esquemática do sistema utilizado nos estudos de degradação redutiva, aplicados no modo continuo. Está disponível em http://quimicanova.sbq.org.br, na forma de arquivo PDF, com acesso livre.

\section{AGRADECIMENTOS}

Ao suporte financeiro do Conselho Nacional de Desenvolvimento Científico e Tecnológico (CNPq), Processo No 474066/2006-1.

\section{REFERÊNCIAS}

1. Kulkarni, M.; Chaudari, A.; J. Environ. Manage. 2007, 85, 496.

2. Bell, L.; Devlin, J.; Gillham, R.; Binning, P.; J. Contam. Hidrol. 2003, 66, 201.

3. Morales, A.; Pérez, M.; Combes, R.; González, M.; Toxicology 2006, $220,51$.

4. Lavine, B.; Auslander, G.; Ritter, J.; Microchem. J. 2001, 70, 69.

5. Soojhawon, I.; Lokhande, E.; Kodam, K.; Gawai, K.; Enzyme Microb. Technol. 2005, 37, 527.

6. Cénas, N.; Céniené, A.; Sergediené, E.; Nivinskas, H.; Anuzevicius, Z.; Sarlauskas, J.; Biochim. Biophys. Acta 2001, 31, 1528.

7. Rocheleau, S.; Kuperman, R.; Martel, M.; Paquet, L.; Bardai, G.; Wong, S.; Sarrazin, M.; Dodard, S.; Gong, P.; Hawari, J.; Checkai, R.; Sunahara, G.; Chemosphere 2006, 62, 545.

8. Rodrigues, M.; da Silva, F.; de Paiva, T.; Quim. Nova 2007, 30, 1623.

9. Morrison, R.; Boyd, R.; Química Orgânica, 13ª ed., Prentice-Hall, Inc.: New Jersey, 1996, cap. 15.

10. Walia, S.; Sadat-A, S.; Chaudhry, G.; Pestic. Biochem. Physiol. 2003, $76,73$.

11. Lachance, B.; Chemosphere 2004, 55, 1339.

12. Momani, F.; J. Photochem. Photobiol. 2006, 179, 184.

13. Phelka, A.; Beck, M.; Philbert, M.; Neurotoxicology 2005, 24, 403.

14. Ramos, J.; Pérez, M.; Caballero, A.; Dillewjin, P.; Biotechnology 2005, 16, 275.

15. Rodrigues, M. B.; Tese de Doutorado, Universidade de São Paulo, Brasil, 2005.

16. Dodard, S.; Renoux, A.; Hawari, J.; Ampleman, G.; Thiboutot, S.; Sunahara, G.; Chemosphere 1999, 38, 2071.

17. Rodgers, J.; Bunce, N.; Water Res. 2001, 9, 2101.

18. Zhang, W.; Chen, L.; Chen, H.; Xia, S.; J. Hazard. Mater. 2006, 153, 348.

19. Tratnyek, P.; Agrawal, A.; Environ. Sci. Technol. 1996, 30, 153.

20. Seok-Young, O.; Chiu, P. C.; Kim, B. J.; Cha, D. K.; Water Res. 2003, $37,4275$.

21. Raja, P.; Bozzi, A.; Jardim, W. F.; Mascolo, G.; Renganathan, R.; Kiwi, J.; Appl. Catal. B: Environ. 2005, 59, 249.

22. Pereira, W.; Freire, R. S.; Quim. Nova 2005, 128, 130.

23. APHA; Standart Methods for Examination of Water and Wastewater, $19^{\text {th }}$ ed., Amer. Publ. Ass.: Washington, 1995, Cap. 3.

24. Matthews, R.; Free Radical Biol. Med. 1995, 18, 919.

25. Hartl, M.; Humph, H.; Food Chem. Toxicol. 2000, 38, 1097.

26. OECD Guidelines for Testing of Chemicals; Inherent Biodegradability: Modified Zahn-Wellens Test, Test 302B, OECD Guidelines for Testing of Chemicals: Paris, 1992.

27. Souza, C. R. L.; Peralta-Zamora, P. G. Quim. Nova 2005, 28, 226.

25. Mu, Y.; Yu, H.; Zheng, J.; Zhang, S.; Sheng, G.; Chemosphere 2004, 54, 789.

26. Chen, J.; Dai, R. J.; Tong, B.; Xiao, S. Y.; Meng, W.; Chinese Chem. Let. 2007, 18, 10.

27. Klausen, J.; Ranke, J.; Schwarzenbach, R.; Chemosphere 2001, $44,511$.

28. Hundal, L. S.; Singh, E. L.; Bier, E. L.; Shea, P. J.; Comfort, S. D.; Powers, W. L.; Environ. Pollut. 1997, 97, 55.

29. Jafarpor, B.; Imhoff, P.; Chiu, P.; J. Contam. Hydrol. 2005, 76, 87.

30. Lavine, B.; Auslander, G.; Ritter, G.; Microchem. J. 2001, 70, 69.

31. Dombek, T.; Dolan, E.; Schultz, J.; Klarup, D.; Environ. Pollut. 2001, $111,21$.

32. Resolução CONAMA No 357 , de 17 de março de 2005.

33. Liou, M-J.; Lu, M-C.; Chen, J-N.; Chemosphere 2004, 57, 1107.

34. Assabane, A.; Ichou, Y. A.; Tahiri, H.; Guillard, Ch.; Herrmann, J. M.; Appl. Catal. B-Environ. 2000, 24, 71. 
DEGRADAÇÃO DE ESPÉCIES NITROAROMÁTICAS E REMEDIAÇÃO DE EFLUENTES DA INDÚSTRIA DE EXPLOSIVOS, UTILIZANDO-SE PROCESSOS REDUTIVOS-OXIDATIVOS FUNDAMENTADOS NO USO DE FERRO METÁLICO

Luiz Fernando Rocha Cavalotti e Patricio Peralta-Zamora*

Departamento de Química, Universidade Federal do Paraná, CP 19081, 81531-990 Curitiba - PR, Brasil

Marcio Barreto Rodrigues

Universidade Tecnológica Federal do Paraná, CP 116, 85503-390 Pato Branco - PR, Brasil

Teresa Cristina Brazil de Paiva

Escola de Engenharia de Lorena, Universidade de São Paulo, CP 116, 12602-810 Lorena -SP, Brasil

Coluna de vidro

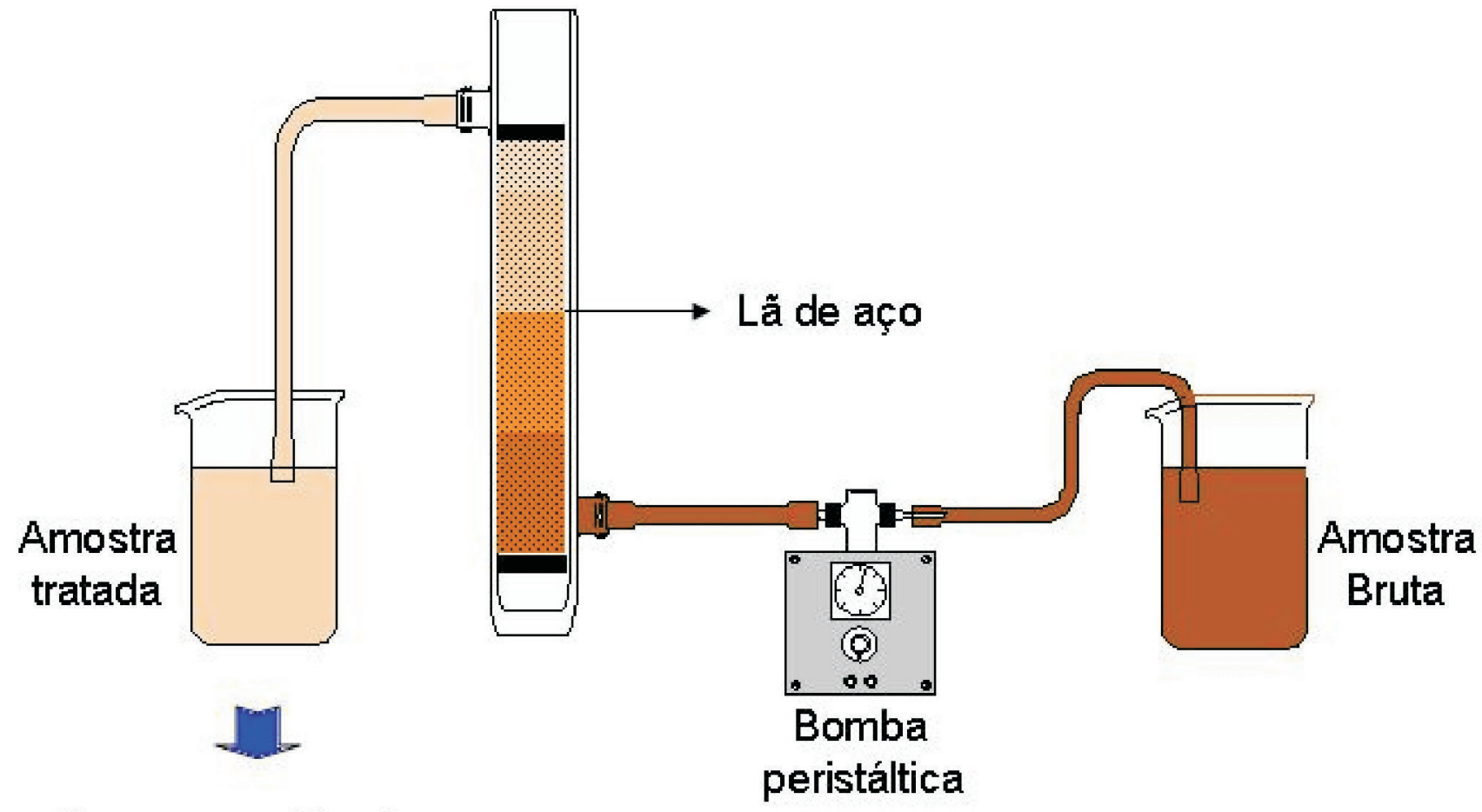

Processo Fenton

Figura 1S. Representação esquemática do sistema utilizado nos estudos de degradação redutiva no modo contínuo

*e-mail: zamora@quimica.ufpr.br 